\title{
Treatment optimisa- tion using external beam radiation in gynaecological cancers
}

V Sharma
MD PhD
U Majeed
FCRad (Onc)
D Joseph
Dip (RT)
S Lindikile
Dip (RLT)
N Madhoo
Nat Dip (D)
Nat Dip (T)
H Copelyn
FCRad (Onc)
J Kotzen
MMed Rad (t)
M Mohiuddin
MMedRad (Onc)
B Donde
MMedRad (t)
Von der Merwe
PhD

\section{Abstract}

The majority of patients with gynaecological cancers present with advanced stages in which external beam radiation forms a major component of the treatment. These patients undergo simulation for treat- ment planning prior to radiation. Currently the lower extent of the disease is evaluated by vaginal examination and marked using a lead wire on the anterior abdominal wall in the pelvic region. A $2 \mathrm{~cm}$ margin inferior to this level is used as the lower border of the treatment field. The suggested modified technique includes the placement of an indigenously designed perspex vaginal obturator with graduations at $1 \mathrm{~cm}$ distance from its tip. Following vaginal examination the obturator can be inserted into the vagina and fixed at the predefined length using a fixation device. The radio-opaque markers can be seen even in the lateral films. Twentyfive consecutive patients underwent the procedure and the differences between the two methods of marking the lower border were calculated. The external lead wire was inferior to the internal obturator in 19 patients (76\%) ranging from $0.5 \mathrm{~cm}$ to $3 \mathrm{~cm}$ (median $1.5 \mathrm{~cm}$, mean $1.37 \mathrm{~cm}$ ). It was at the same level in 4 patients (16\%) and $1 \mathrm{~cm}$ superior to the internal obturator in 2 (8\%). With the modified technique using the internal obturator application for delineating the lower border of vaginal disease or vault, it was possible to decrease the length of field thereby reducing the chances of treatment-related toxicity, especially groin and vulval reactions, as well as avoiding treatment interruptions.

\section{Introduction}

The majority of patients with gynaecological cancer require external beam radiation to the pelvis as a major component of their treatment. ${ }^{1,2}$ The lower border of the treatment field is determined following vaginal examination and assessment of the extension of the disease into the vagina. The purpose of the modified technique is: (i) to accurately assess the lower extent of the disease and define the lower border of the external radiation field in both the anteroposterior/ posteroanterior (AP/PA) and lateral fields; and (ii) to decrease the field size and reduce treatment-related side-effects.

\section{Methods and materials}

Twenty-five consecutive patients scheduled to undergo external beam radiation therapy for postoperative treatment of gynaecological cancers (carcinoma of the cervix and body of the uterus) underwent the modified technique of insertion of a vaginal obturator. The patients underwent vaginal examination at the simulator. The lower border of the disease was noted and the distance from the introitus was measured. The obturator was then adjusted to that distance using the graduated markings and was fixed with a fixation device to prevent it being pushed in by changes in the position of the legs. Using the present technique, after the lower extent of disease has been noted, an external leadwire marker is placed over the 


\section{ORIGINAL ARTICLE}

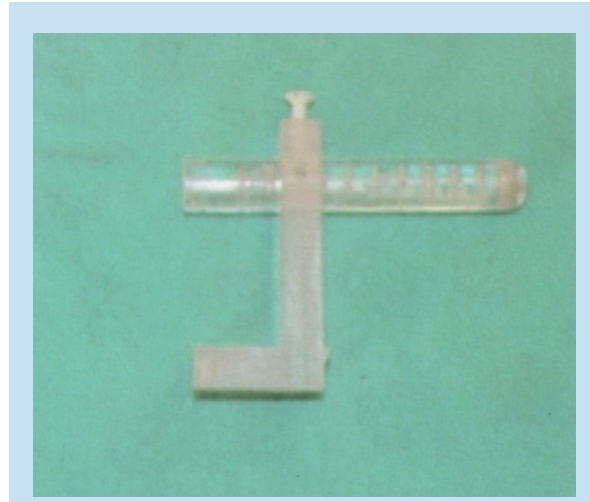

Fig. 1. The vaginal obturator (indigenously designed).
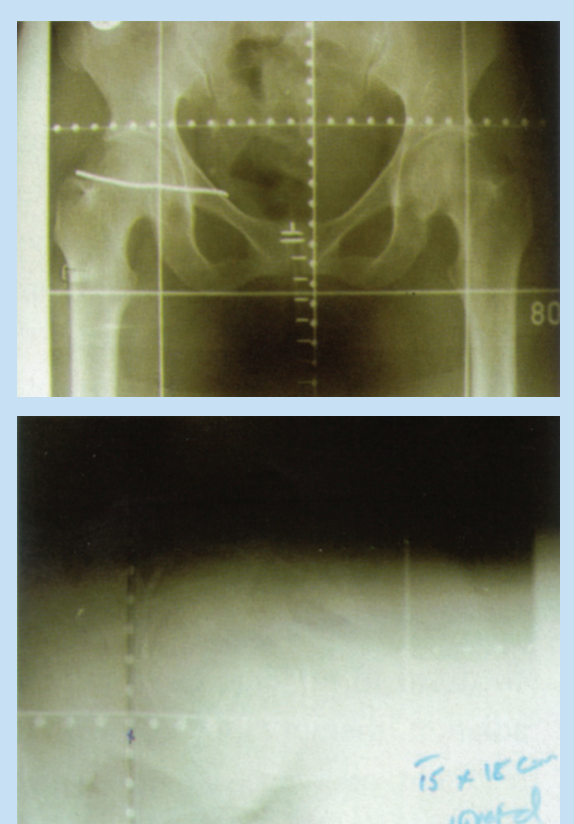

Fig. 2. Simulator films: AP view/lateral view show ing both the external wire and the internal obturator.

anterior abdominal wall in the pelvic region. The lower border of the external field is $2 \mathrm{~cm}$ below the leadwire marker as seen on the simulator. All 25 patients had placement of the external lead wire as well as the internal vaginal obturator. (Figs 1, 2a and 2b). The obturator and the external wire mark-

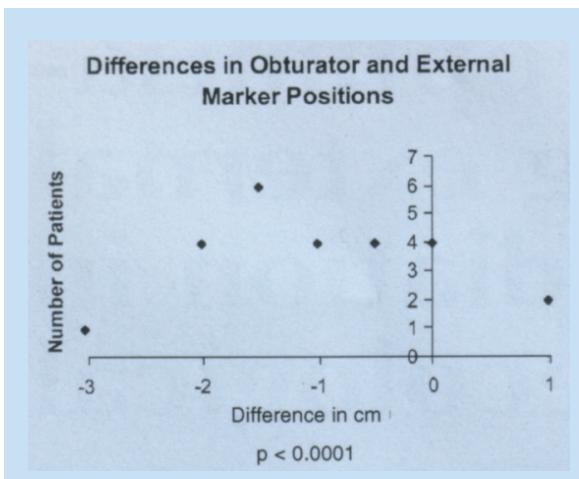

Fig. 3. Differences in obturator and external marker position.

ers were placed by different clinicians to eliminate bias. Fig. 3 shows the estimated difference (inferior, at the same level and superior) of the external wire marker from the internal vaginal obturator which was taken as level ' 0 '.

\section{Results}

The external wire marker was 0.5 $3 \mathrm{~cm}$ inferior to the internal obturator in 19 patients $(76 \%)$ (median $1.5 \mathrm{~cm}$ and mean $1.37 \mathrm{~cm}$ ), at the same level in $4(16 \%)$ and superior by $1 \mathrm{~cm}$ in 2 (8\%) as seen on the AP/PA simulator films (Figs 1 and 2a). The external wire was not visible in the lateral films (Fig. 2b).

\section{Discussion}

Most patients with gynaecological cancers present with advanced stages in which external beam radiation is the main component of treatment., ${ }^{1,2}$ The treatment field size used should be optimised to control the disease with minimum side-effects. An external marker is not as accurate as an internal marker for two reasons: (i) there will be additional divergence of the beam from an external marker in comparison with an internal marker which is dependent on the anterior posterior separation of the patient; and (ii) the placement of the external marker is less accurate and more dependent on the experience of the treating physician. The modified procedure of using an internal obturator will optimise the field size and also help in localisation of the centre of the field as recommended ${ }^{3}$ for postoperative treatments.

The advantages of the modified technique are: (i) accurate assessment of the vaginal extent of the lesion; (ii) reduction of treatment-related sideeffects in the groin and perineum enabling completion of the treatment in the prescribed time; and (iii) it is simple to perform and is easily reproducible.

\section{Conclusion}

The accurate assessment of the lesion on simulator X-rays (AP/PA and lateral film) will provide adequate coverage of the disease as well as help in reducing the toxicity of the treatment. The change in clinical practice at our centre should also be evaluated by others.

\section{References}

1. Dinshaw KA, Rao DN, Shroff PD. Hospital based cancer registry, Mumbai, India. Tata Memorial Hospital, 1998: 52.

2. Dinshaw KA, Shrivastava SK, Muckaden MA Sharma V, Deore SM, Viswanathan PS. Factors influencing treatment strategies using MDR brachytherapy for cervical cancer. In: Mould RF Battermann JJ, Martinez AA, Speiser BL, eds. Brachytherapy from Radium to Optimization. Veenandaal, Netherlands: Nucletron International, 1994: 67-78

3. Glassburn JR, Brady LW, Grisby PW. Endometrium. In: Perez CA, Brady LW, Halperin EC, Schmidt-Ullrich RK, eds. Principles and Practice of Radiation Oncology. Philadelphia: Lippincott Williams \& Wilkins, 2004: 1916-1933. 